\title{
Evaluating the Influence of Conspecifics on a Male Giant Anteater's (Myrmecophaga tridactyla) Pacing Behavior
}

\begin{abstract}
Adrienne E. Eyer, ${ }^{1,2}$ and Lance J. Miller,"*
${ }^{1}$ Project Dragonfly, Miami University

${ }^{2}$ Animal Welfare Research, Chicago Zoological Society

*Corresponding author (Email: Lance.Miller@CZS.org)

Citation - Eyer, A. E., \& Miller, L. J. (2020). Evaluating the influence of conspecifics on a male giant anteater's (Myrmecophaga tridactyla) pacing behavior. Animal Behavior and Cognition, 7(4), 556-566. doi: https://doi.org/10.26451/abc.07.04.07.2020

Abstract - Stereotypic behavior has been studied in various species, but little information exists on stereotypies in giant anteaters (Myrmecophaga tridactyla) under professional care. Giant anteaters are known for their solitary nature and well-developed sense of smell. This study examined the effect of conspecifics who were housed offexhibit on a male giant anteater's rate of pacing and pacing intensity when he was on-exhibit. Instantaneous sampling was used to determine the percentage of time pacing, the number of pacing bouts and pacing bout duration. Randomization tests determined that the reduction in the male giant anteater's rate of pacing significantly decreased after conspecifics were relocated to a different building. Pacing bout duration, a potential measure of intensity, also significantly decreased during the treatment phase. In addition, the giant anteater changed his pacing location after the removal of conspecifics. He transitioned from pacing near the conspecifics' off-exhibit location during the baseline to the opposite quadrant of the exhibit after their departure. These results suggest that keeping a male giant anteater in proximity to conspecifics without the ability to interact with them had an impact on his behavior. Better understanding the motivations for stereotypic behaviors of giant anteaters will better inform housing decisions made by zoo professionals.
\end{abstract}

Keywords - Animal behavior, Animal welfare, Neighbors, Stereotypies, Pilosa, Xenarthrans

As zoological institutions strive to optimize the welfare of animals under professional care, they are continuously seeking new knowledge about the species within their collections (Ward et al., 2018). Pioneers in animal welfare research began the transformation from reproduction-oriented husbandry programs to more holistic care that incorporated new behavioral information from in-situ research. The field of animal welfare progressed further when zoos started forming their own behavioral research departments to improve the welfare of their collections (Powell \& Watters, 2017). Former husbandry protocols have been replaced with a more complex portfolio of practices monitoring the physical, mental, and emotional health of individuals under professional care (Whitham \& Miller, 2019) which sometimes extends to temperament testing of animals to better anticipate how the individual might react to challenges in its environment (Shepherdson et al., 2013). The behavioral information gathered about individuals under professional care can help inform management decisions on husbandry regimens and exhibit design to improve well-being (Rose et al., 2017b). The decades-long transformation in animal welfare science has incorporated natural history as an integral component to achieving improved welfare for species under professional care (Powell \& Watters, 2017). However, not all species are studied 
equally and the giant anteater (Myrmecophaga tridactyla) is considered a charismatic yet understudied species (Diniz \& Brito, 2012).

Diniz and Brito (2012) determined that most research existing on giant anteaters aimed to answer questions on ecology and morphology rather than behaviors of individuals under professional care in zoos. When studying behavior, whether naturalistic or stereotypic, ethologists describe behaviors as an indicator of how an individual relates to its environment (McPhee \& Carlstead, 2010; Schmidt, 2012). Stereotypies are repetitive behaviors with no discernable function (Mason, 1991), and pacing is one of the most common stereotypies in mammals under professional care (Cless et al., 2015). For example, species that have large bodies, vast ranges, and long daily journeys are more at-risk of pacing when they reside in zoos than species that do not share those traits (Clubb \& Mason, 2003). Species with complex foraging and hunting techniques in their natural habitat tend to be more at-risk to the development of stereotypies in zoo environments (Bauer et al., 2013). A species' proximity to conspecifics can also be a risk factor for stereotypic behavior depending on their social status in their natural habitat (solitary or social) and their housing arrangement while under professional care (Mason et al., 2007). Finally, a species' natural use of their senses can contribute to their risk factors for stereotypies; for example, an individual who relies on olfactory cues might be overstimulated or understimulated in a zoo environment and therefore at higher risk for developing stereotypic behaviors (Morgan \& Tromborg, 2007).

Even if risk factors for pacing are understood for a species or individual, pacing may still arise in animals under professional care and should be evaluated to uncover the cause and understand the effect on the animal's welfare (Mason, 1991). Motivations (or causes) for pacing are diverse and are not the same for every species or individual. Different species might have different motivators while individuals might have different triggers at different times or in different scenarios (Bauer et al., 2013). The logical starting point for any type of species, including the giant anteater, is to determine the individual's pacing motivation through the lens of risk factors determined by its natural history (Rose et al., 2017a).

The giant anteater is a Xenarthran with a distinctive morphology and large body mass of 22 to 39 $\mathrm{kg}$ in the wild. Their large front claws, long snout, toothless mouth and thin tongue (Gaudin et al., 2018) make them a specialist in foraging for ants and termites (Bertassoni \& Milléo Costa, 2010; Eisenberg \& Redford, 1999; Gaudin et al., 2018). They have poor eyesight and hearing (Eisenberg \& Redford, 1999; Mouráo \& Medri, 2007), but an acute sense of smell (Bertassoni \& Milléo Costa, 2010; Eisenberg \& Redford, 1999; Gaudin et al., 2018). The giant anteater's highly developed sense of smell is effective for specialized foraging and various types of communication (Gaudin et al., 2018; Rodrigues et al., 2008). The solitary giant anteater's home range $\left(0.72 \mathrm{~km}^{2}-32.5 \mathrm{~km}^{2}\right)$ is dependent on location, gender, and extrinsic factors such as seasonality and human impact (Bertassoni \& Ribeiro, 2019; Rodrigues et al., 2008). Location and outside forces also lead to variability in density. Kreutz and colleagues (2012) estimated 2.9 individuals $/ \mathrm{km}^{2}$ on converted plantations while Desbiez and Medri (2010) calculated 0.15 individuals $/ \mathrm{km}^{2}$ in an area of Brazil's Pantanal region with little anthropogenic disturbance. Overlap in home ranges is more tolerated by females than males (Bertassoni \& Ribeiro, 2019; Shaw et al., 1987). Catapani and colleagues (2019) describe three tolerant encounters involving females and pups. In two cases, both adults were females carrying pups. In the third case, one adult was a female carrying a pup foraging near a tolerant conspecific of unknown gender. Conversely, there is a longer history of documenting agonistic interaction with conspecifics during chance encounters that typically coincide with foraging (Kreutz et al., 2009; Miranda Junior \& Bertassoni, 2014; Rocha \& Mourao, 2006; Shaw et al., 1987). Various researchers have described the agonistic encounters similarly with giant anteaters detecting each other through olfaction, circling, chasing, and exchanging blows until one of the anteaters flees after injuries are sustained by one or both individuals (Kreutz et al., 2009; Miranda Junior \& Bertassoni, 2014; Rocha \& Mourao, 2006; Shaw et al., 1987). The agonistic encounter described by Miranda Junior and Bertassoni (2014) was confirmed to be between a male and female carrying her cub.

The giant anteater's solitary nature and reliance on its acute sense of smell has provided zoos some key factors to consider as caregivers work to optimize the welfare of this species when under professional care. Zoos have attempted to meld the individual's needs as directed by their natural history (Rose et al., 2017b) with an artificial environment which can lead to behavioral restrictions sometimes 
followed by stereotypic behaviors (Shepherdson et al., 1993). Zoo environments lacking in complexity have been linked to increased stereotypies in small felids (Shepherdson et al., 1993) and various types of bears (Swaisgood et al., 2001; Tan et al., 2013). An environment that does not honor a species' social status has also been linked to increased rates of stereotypic behaviors in both solitary and social species (De Rouck et al., 2005; Troxell-Smith \& Miller, 2016). Even when the individual's proximity to conspecifics has been actively managed, stereotypies can arise as some animals can be influenced by olfactory cues from conspecifics even when not in their direct presence (Morgan \& Tromborg, 2007). Miller and colleagues (2008) have suggested that pacing could be a redirected behavior when solitary animals have the ability to view but not interact with conspecifics.

Because behavioral acts, including stereotypic behavior, are an indicator of how an individual relates to its environment (McPhee \& Carlstead, 2010; Schmidt, 2012), the cause(s) of stereotypies must be determined to ensure optimized welfare for an individual under the care of zoo professionals (Mason, 1991). Literature exists on the natural behaviors of giant anteaters in zoos but understanding stereotypies specific to giant anteaters is lacking. Since the location of the male giant anteater's pacing behavior suggested proximity to conspecifics could be a factor, the objective of this study was to determine if conspecifics influenced the pacing behavior of the male giant anteater under professional care. The hypothesis was that removal of conspecifics would decrease the male giant anteater's rate of pacing.

\section{Method}

\section{Subject}

The subject of this study was a seven-year-old male giant anteater weighing $62 \mathrm{~kg}$. He was born in 2012 at Nashville Zoo in Tennessee, dam-reared, and transferred to Chicago Zoological Society's Brookfield Zoo in 2014. At the time of this study, he had resided at Brookfield Zoo's Tropic World for 5 years. Of the three giant anteaters residing at Brookfield Zoo, the adult male was selected for this study because he was the only anteater displaying a pacing behavior.

\section{Exhibit}

At Brookfield Zoo, giant anteaters are housed in Tropic World's South America exhibit which is an indoor, climate-controlled, multi-species, hard-surfaced enclosure with approximately 5,600 $\mathrm{ft}^{2} \mathrm{of}^{\circ}$ publicly viewable habitat. The male giant anteater rotates on and off exhibit in a "timeshare" arrangement (Coe, 2004, p. 2) with a female giant anteater and pup who was born in December, 2018. When the male anteater is on-exhibit, the female and pup are off-exhibit and vice versa. The on-exhibit space is adjacent to the off-exhibit housing for the giant anteaters with a single wall containing shift doors separating the conspecifics. A schematic of Tropic World can be found in Figure 1. In addition to the three giant anteaters, Tropic World's South America is home to various New World monkeys and sloths including black-handed spider monkeys (Ateles geoffroyi), Geoffroy's marmosets (Callithrix geoffroyi), golden lion tamarins (Leontopithecus rosalia), Goeldi's monkeys (Callimico goeldii), squirrel monkeys (Saimiri sciureus) and Hoffman's two-toed sloths (Choloepus hoffmanni). Several species of birds also reside in the exhibit including blue-gray tanagers (Thraupis episcopus), troupials (Icterus icterus), turquoise tanagers (Tangara mexicana), saffron finches (Sicalais flaveola) and red-capped cardinals (Paroaria gularis). The exhibit's multi-species design impedes the giant anteater(s) from crossing paths with most species in the exhibit with exception of the spider monkeys and squirrel monkeys.

\section{Study Design}

A single-case $\mathrm{AB}$ design, including baseline and treatment phases, was used to test if the presence of conspecifics influenced the male giant anteater's time pacing, pacing intensity and space-use within the 
exhibit. During the baseline phase, he was on-exhibit while the female giant anteater and their pup resided off-exhibit in the same building. The treatment phase began after the female giant anteater and pup were moved to a different building. A defined ethogram described in Table 1 was used to record four different behaviors: Active-Not Pacing, Active-Pacing, Not Active, and Out-of-View.

\section{Figure 1}

\section{Schematic of Tropic World, South America Exhibit, Brookfield Zoo}

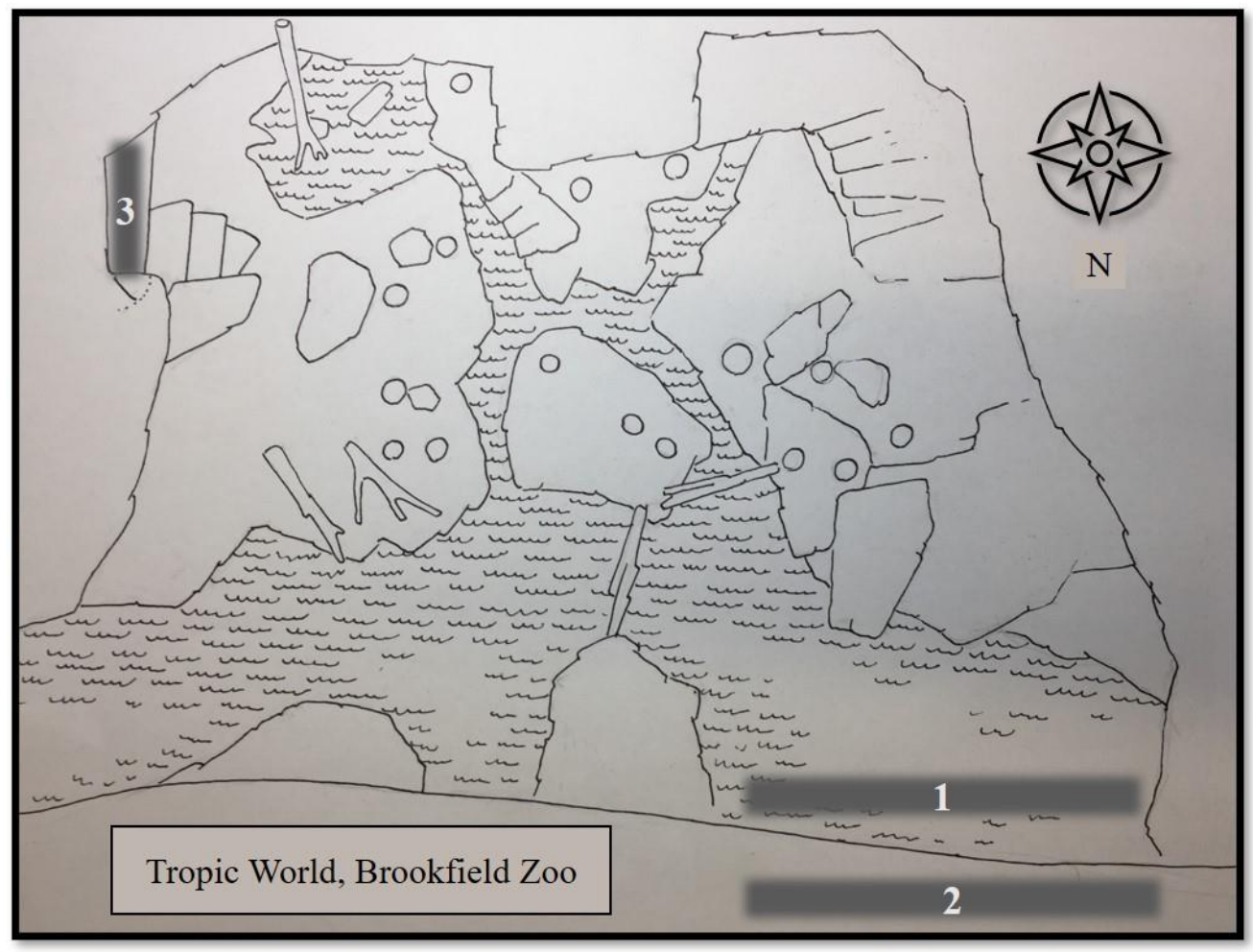

Note. 1 = location of pacing behavior of male giant anteater during baseline phase; 2 = off-exhibit location of female giant anteater and cub during baseline phase; 3 = location of pacing behavior of male giant anteater during second data collection period of treatment phase.

\section{Table 1}

Description of the Four Ethogram Choices Available to the Observer

\begin{tabular}{ll}
\hline Ethogram choice & \multicolumn{1}{c}{ Behavior description } \\
\hline Active - Not Pacing & $\begin{array}{l}\text { Any active state that did not include pacing. This included alert (stand), locomotion (walk, run, } \\
\text { turn, climb, swim), foraging (investigate, smell, dig), feeding (eat, drink), grooming (self-smell, } \\
\text { scratch, rub, snout clean, bathe), and excreting behaviors. }\end{array}$ \\
Active - Pacing $^{2}$ & $\begin{array}{l}\text { Active locomotion traversing the same path a minimum of } 2 \text { times with pacing beginning after the } \\
2^{\text {nd }} \text { turn while not engaging in other activity except smelling. }\end{array}$ \\
Not Active & Motionless states including sitting, laying, or sleeping. \\
Out-of-View & Not visible to observer. \\
\hline
\end{tabular}

Note. 1,2 "Active - Not Pacing" and "Not Active" descriptions modeled after behavior descriptions defined in Schmidt (2012).

"Active - Pacing" description (excluding smelling activity) modeled after pacing definition by Miller et al. (2008). 
To minimize observer bias, pacing was defined as traveling the same path a minimum of two times with pacing beginning after the second turn (Mellen et al., 1998; Miller et al., 2008). As Schmidt (2012) recommends, further definition was utilized to ensure pacing was recognizable without confusion. If the male giant anteater paused for less than $10 \mathrm{~s}$ but stayed on the same path with the same body direction, he was considered to still be pacing (Miller et al., 2008). Breaking pace was defined as leaving the path, pausing for longer than $10 \mathrm{~s}$, or engaging in a different behavior.

\section{Data Collection}

The male giant anteater's behavior and location coordinates were captured using ZooMonitor software on a handheld tablet using the defined ethogram (Table 1) and an aerial view of the exhibit (Figure 1; Wark et al., 2019). ZooMonitor's "Interval" mode was used to collect data in $15 \mathrm{~min}$ observation sessions with one-minute intervals (Altmann, 1974; Wark et al., 2019). This process was repeated nine times per day resulting in 135 data points collected between 10:15 AM and 3:15 PM each day. ZooMonitor's administrative mode allowed the user to transfer the data from the tablet to Microsoft Excel after data were collected (Wark et al., 2019). The observer collected data for 11 days during the baseline phase between June 17, 2019 and July 1, 2019. Treatment data were collected for 22 days between July 2, 2019 and August 30, 2019. The treatment data were collected during two distinct periods consisting of 12 days in the beginning of the treatment phase and 10 days at the end of the treatment phase with a four week break in between. The break between data collection periods was to determine if the rate of pacing would continue to decrease or plateau over time. A single observer using a defined ethogram collected all data and eliminated the need for inter-observer reliability testing. Due to the short nature of the project at two months duration, intra-observer reliability was not conducted or considered necessary.

\section{Analysis}

Descriptive statistics for each phase were calculated to determine the male giant anteater's percentage of visible scans in active-pace referred to as "active-pace" from this point forward. The rate of active-pace was calculated by taking the number of minutes pacing divided by the total minutes viewable by the observer (active-pacing, active-not pacing, and not active). The rate of active-pace was calculated for each full day as well as morning and afternoon periods. Descriptive statistics were also calculated for the average pacing bout duration and the average number of bouts per day. Average daily bout length was calculated by dividing the number of daily visible scans in active-pace by the number of daily bouts. A frequency distribution for bout lengths was constructed to compare bout length between each data collection period.

Randomization tests specific to single-case $A B$ studies were conducted to determine if the difference between phase means was significant. All randomization tests performed created a random sample of 2,000 rearrangement statistics to determine the significance of our experiments' test statistics (Dugard et al., 2012). Because the treatment phase had two data collection periods, randomization tests were performed to confirm that the data collection periods could be combined as a single data set for the treatment phase for each variable (average rate of active-pace, average number of daily bouts and average bout duration). The separate data collection periods during the treatment phase had mean differences of $0.75 \%$ (rate of active-pace), -0.43 (average number of daily bouts), and 2.43 min (average bout duration). The randomization tests for all 3 variables determined there was no significant difference in means between the two data collection periods for each variable $(p>.05)$. Therefore, the separate data sets for each variable (rate of active-pace, average number of daily bouts, average bout duration) were combined into a single data set representing the treatment phase for further analysis. After confirming a single data 
set for the treatment phase, another randomization test was run to determine if the difference between the baseline and treatment means was significant for each variable.

To analyze exhibit location preferences, the male giant anteater's location coordinates were analyzed using only his location during active times to determine how he used his available space. His percentage of time spent at each coordinate was calculated as total minutes in Active-Pace at a specific coordinate divided by total minutes in Active-Pace for the entire exhibit for each day. Active-Not Pacing was calculated using the same methods.

\section{Results}

\section{Pacing}

The male giant anteater's rate of active-pace dropped from $60.00 \%$ during the baseline $(n=11$ days) to $43.52 \%$ during the treatment phase $(n=22$ days) resulting in a difference of $16.48 \%$ between phases as shown in Table 2. Additional descriptive statistics shown in Table 2 subdivide the daily rate of active-pace into morning and afternoon rates. The AM and PM rates of active-pace both decreased, however, the morning reduction made a larger contribution to the daily reduction of active-pace. The onetailed randomization test that compared the difference in phase means for rate of active-pace determined the reduction in means was significant $(p=.04)$.

Table 2

Pacing Statistics by Phase

\begin{tabular}{|c|c|c|c|c|c|c|c|c|}
\hline & \multicolumn{2}{|c|}{ Daily Pacing } & \multicolumn{2}{|c|}{ AM Pacing } & \multicolumn{2}{|c|}{ PM Pacing } & \multicolumn{2}{|c|}{ Daily Bout Duration } \\
\hline & Mean $(\%)$ & SD & Mean $(\%)$ & $\mathrm{SD}$ & Mean $(\%)$ & $\mathrm{SD}$ & Mean (min) & $\mathrm{SD}$ \\
\hline $\begin{array}{l}\text { Baseline } \\
(\mathrm{n}=11 \text { days })\end{array}$ & 60.00 & 10.15 & 51.76 & 16.42 & 62.27 & 10.72 & 4.57 & 0.95 \\
\hline $\begin{array}{l}\text { Treatment All } \\
(\mathrm{n}=22 \text { days })\end{array}$ & 43.52 & 7.79 & 32.58 & 16.69 & 52.12 & 8.56 & 3.65 & 0.80 \\
\hline $\begin{array}{l}\text { Treatment } 1^{b} \\
(\mathrm{n}=12 \text { days })\end{array}$ & 43.18 & 7.41 & 31.67 & 17.21 & 52.11 & 10.04 & 3.85 & 0.83 \\
\hline $\begin{array}{l}\text { Treatment } 2^{\mathrm{c}} \\
(\mathrm{n}=10 \text { days })\end{array}$ & 43.93 & 8.20 & 33.67 & 15.97 & 52.13 & 6.35 & 3.42 & 0.70 \\
\hline
\end{tabular}

Note. Daily Pacing = the number of minutes pacing divided by the total minutes viewable by the observer (active-pacing, active-not pacing, and not active) for each day; AM Pacing = the number of minutes pacing divided by the total minutes viewable by the observer (active-pacing, active-not pacing, and not active) for each day between 10:15am and Noon; PM Pacing = the number of minutes pacing divided by the total minutes viewable by the observer (active-pacing, active-not pacing, and not active) for each day between 1:00pm and 3:15pm; Daily Bout Duration $=$ the number of daily visible scans in active-pace divided by the number of daily bouts

${ }^{a}$ All treatment data combined into a single data set after randomization tests specific to single-case AB studies determined the difference between separate data collection periods was not significant $(p>.05)$.

${ }^{\mathrm{b}}$ Treatment data collected between July 2, 2019 and July 19, 2019

${ }^{\mathrm{c}}$ Treatment data collected between August 19, 2019 and August 30, 2019

The average number of pacing bouts was not statistically significant $(p>.05)$ when comparing the baseline average $(M=18.00, S D=3.10)$ and treatment average $(M=16.77, S D=4.69)$. The average duration of bouts decreased by 0.94 min when comparing the baseline $(M=4.57, S D=0.95)$ and treatment $(M=3.63, S D=0.80)$. The frequency distribution of bouts and their duration shows that shorter bouts became more frequent as the study progressed while longer bouts declined throughout the study (Figure 2). The one-tailed randomization test comparing average bout duration between the baseline and treatment phases determined the reduction in bout length was significant $(p<.05)$. 
Figure 1

Distribution of Pacing Bouts by Bout Duration

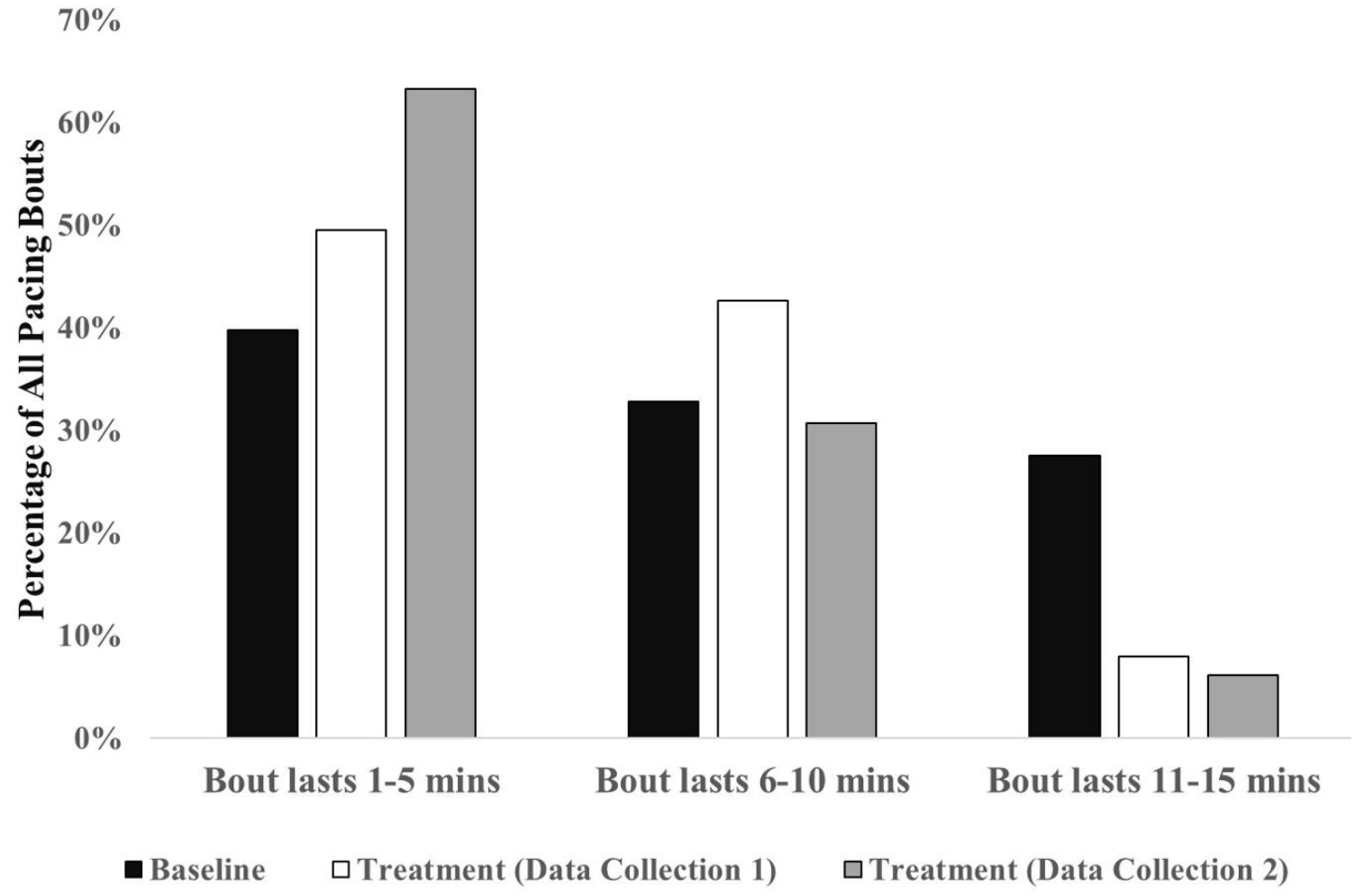

\section{Space Use}

During the baseline phase, the male giant anteater paced in three separate quadrants of the exhibit. During baseline, $93.13 \%$ of the pacing occurred in the northwest quadrant. When his rate of active-pace dropped in the first part of the treatment phase, the giant anteater spent $88.09 \%$ of his time pacing in the northwest quadrant. However, when data collection resumed in the latter part of the treatment, the location for pacing had changed to $99.83 \%$ of his time in active-pace in the southeast quadrant of the exhibit. Space-use data presented in Table 3 illustrate his transition from three separate locations during the baseline to a single location in the final data collection period of the study.

Table 3

Space-Use: Percentage of Visible Scans in Active-Pace by Exhibit Quadrant

\begin{tabular}{llll}
\hline Quadrant & $\begin{array}{l}\text { Baseline Active-Pace } \\
(M=60.00 \%, n=11 \text { days })\end{array}$ & $\begin{array}{l}\text { Treatment Active-Pace } \\
\text { Data Collection 1 } \\
(M=43.18 \%, n=12 \text { days })\end{array}$ & $\begin{array}{l}\text { Treatment Active-Pace } \\
\text { Data Collection 2 } \\
(M=43.93 \%, n=10 \text { days })\end{array}$ \\
\hline Northwest & $93.13 \%$ & $88.09 \%$ & $0.17 \%$ \\
Northeast & $5.07 \%$ & $6.31 \%$ & $0.00 \%$ \\
Southwest & $0.00 \%$ & $0.00 \%$ & $0.00 \%$ \\
Southeast & $1.69 \%$ & $5.60 \%$ & $99.83 \%$ \\
\hline
\end{tabular}




\section{Discussion}

The results of this study suggest that the male giant anteater paced at a significantly higher rate and intensity (measured by bout duration) adjacent to the conspecifics residing off-exhibit during the baseline phase than during the treatment phase. His transition to a different location in the opposite quadrant of the exhibit also supports the hypothesis that the conspecifics influenced the amount of time he spent pacing. The characteristics of stereotypic pacing and location of the behavior can give some indication of the motivation or cause behind that behavior (Bauer et al., 2013; Cless \& Lukas, 2017).

Using average bout duration as a proxy for pacing intensity provides additional support that conspecifics influenced the male giant anteater's pacing. His significant reduction in pacing intensity per bout coevolved with the reduction in his rate of active-pace. Having two separate measurements for pacing can provide insight into the underlying motivation for pacing and how the behavior might vary relative to the motivator(s) (Cless \& Lukas, 2017). In the case of the male giant anteater, the presence of conspecifics was tied to both the behavior and the more intense presentation of the behavior. The initial reduction in the active-pace behavior was due to the removal of the conspecifics, however, the less intense pacing in a new location implies the giant anteater's pacing stems from multiple motivations.

Uncovering additional motivation(s) for pacing in a new location requires revisiting natural history along with understanding implications of a behaviorally restricted environment (Rose et al., 2017b). The giant anteater's naturally large home range and long daily journey (Bertassoni \& Ribeiro, 2019) are known risk factors for developing stereotypies in a restricted habitat (Clubb \& Mason, 2003). Pacing that occurs along the edges of exhibits, like the giant anteater's original pacing location and new location (Figure 1), has been linked to the same risk factors and attributed to frustration arising from the animal's inability to leave the exhibit (Cless \& Lukas, 2017). The desire to leave the exhibit typically falls into one of three categories: escaping, exploring to fulfill physical needs (food, weather relief, rest), or investigating outside influences (predator, prey, conspecifics). When escape, exploration or interaction with other animals is prevented by the boundaries of the exhibit, the individual may replace the desired activity with stereotypic behavior (Shepherdson, 1989).

Similar to the male giant anteater, stereotypies in other animals under human care have also been linked to the inability to interact with conspecifics detected beyond their exhibit's boundaries. Pacing in tigers (Panthera tigris), typically a solitary species, was linked to conspecifics in their line of sight by De Rouck et al. (2005) and Miller et al. (2008). Similarly, okapis (Okapia johnstoni) have also displayed stereotypies, specifically head-rolling, that were linked to their housing arrangements near conspecifics (Troxell-Smith \& Miller, 2016). Neither species was able to interact with conspecifics detected beyond their physical boundary. For tigers and okapis, the researchers determined that exhibit modifications affecting line of sight to their conspecifics reduced the stereotypic behavior. In the case of the black rhinoceros (Diceros bicornis), also heavily dependent on olfaction, not being able to reach conspecifics was tied to agitated states resulting in recommendations to review husbandry practices (Carlstead et al., 1999).

While there are many potential causes for the pacing behavior still observed in the anteater during the treatment, it is likely something to do with the current environment. Wild giant anteaters spend approximately $89 \%$ of their time foraging, feeding, resting, excreting, snout cleaning, grooming, and scratching. Their counterparts living in a zoo under professional care spend approximately $51 \%$ of their time on the same behaviors (Bertassoni \& Milléo Costa, 2010). When filtering their maintenance behaviors for those that require olfaction, wild giant anteaters spend $51 \%$ of their activity budget on olfaction-oriented behaviors associated with foraging while their zoo-housed counterparts spent $28 \%$ of their activity budget on the same behaviors ${ }^{1}$ (Bertassoni \& Milléo Costa, 2010). It is possible that a more complex environment affording more behavioral opportunities could further decrease this behavior.

\footnotetext{
${ }^{1}$ Olfaction-oriented behaviors were derived by combining data from two foraging behaviors, sniffing and snout near soil, as defined by Bertassoni and Milléo Costa (2010).
} 
Schmidt (2012) also examined the behavior of zoo-housed giant anteaters and concluded that a more complex environment was needed to reduce the stereotypies of the resident giant anteaters. According to Allard and colleagues (2014), creating a complex environment that promotes more natural foraging should incorporate the giant anteater's use of spatial memory to locate food and their high level of cognition for safely removing insects from nests.

Integrating the results of this study and the established body of work on stereotypic behavior in zoo-housed individuals suggests a multi-pronged approach is likely necessary to reduce the giant anteater's pacing depending on the individual and the facility. While an acute event could be the cause for stereotypic behavior, the behavior could become ritualized or continue for an unrelated reason (Bauer et al., 2013). Pacing has been attributed to past events (Swaisgood \& Shepherdson, 2005), temperament of the animal (Shepherdson et al., 2013), or even changes in neural circuitry (Bauer et al., 2013; Cless et al., 2015). Stereotypies can quickly become reinforced behaviors (Mason, 1991) and animal welfare scientists advocate for addressing underlying motivations whether tied to natural or individual history rather than simply finding ways to prevent the behavior (Mason et al., 2007). Stereotypies are not always correlated to diminished welfare; however, they are viewed as an indicator that warrants investigation (Swaisgood \& Shepherdson, 2005).

Zoological institutions have the potential to minimize stereotypies, increase natural behaviors and optimize the welfare of giant anteaters through a more complex environment by integrating their natural history and individual history into decisions around exhibit design, husbandry routines and housing arrangements with respect to conspecifics. Future research should examine possible causes for the new findings such as the difference between morning and afternoon pacing reductions, his change in location and the impact of increasing the complexity of his environment. The male giant anteater residing at Brookfield Zoo benefitted from the removal of conspecifics, however, before making a recommendation for other giant anteaters under professional care, a multi-institutional study with a larger sample size should be considered. With a larger sample size, a multi-institutional study could provide more insight on the role gender plays on behavior when conspecifics are detected. In-situ studies acknowledge that lack of sexual dimorphism prohibit researchers from confirming gender during agonistic and tolerant encounters unless the individual is caring for a pup or has been tagged or fitted with a transmitter (Catapani et al., 2019; Shaw et al., 1987). Research conducted at zoos could benefit zoo-housed giant anteaters as well as field researchers when considering topics such as tolerance of conspecifics or the role of gender in encounters. This could also lead to better understanding tolerance between conspecifics when pups are involved. A multi-institutional study could also help determine the correlation between various measurable characteristics of pacing (rate, intensity, location) and underlying motivators of pacing.

Reducing stereotypies and optimizing welfare is a non-linear, complex process requiring a solid understanding of an individual's natural history (Rose et al., 2017b), individual history (Shepherdson et al., 2013) and cognitive abilities (Allard et al., 2014). Using that understanding as a starting point allows zoos to ensure they are providing a complex environment by targeting species-specific behaviors (Rose et al., 2017b) through exhibit design, husbandry routines and proximity to conspecifics (Whitham \& Miller, 2019). A complex exhibit meeting the physical, mental and emotional needs of an individual taking into consideration factors both inside as well as outside an animal's habitat can help lead to optimized welfare (Whitham \& Miller, 2019).

\section{Acknowledgements}

We would first like to thank Sarah Breen-Bartecki, Bill Zeigler and Amy Roberts for their continued support. Additionally, we would like to thank all of the Tropic World staff for their assistance during the study. We would also like to thank Miami University's Project Dragonfly for their support of this behavioral study through guidance during an internship and independent study for Eyer's master's degree. 


\section{References}

Allard, S. M., Earles, J. L., \& DesFosses, L. (2014). Spatial memory in captive giant anteaters (Myrmecophaga tridactyla). Animal Behavior and Cognition, 1, 331-340.

Altmann, J. (1974). Observational study of behavior: Sampling methods. Behaviour, 49, 227-267.

Bauer, E., Babitz, M., Boedeker, N., \& Hellmuth, H. (2013). Approaches to understanding and managing pacing in sloth bears in a zoological setting. International Journal of Comparative Psychology, 26, 53-74.

Bertassoni, A., \& Milléo Costa, E. L. (2010). Behavioral repertoire of giant anteater (Myrmecophaga tridactyla, Linnaues 1758) in nature at Serra da Canstra National Park, MG and in captivity at Curitiba Zoo, PR, Brazil. Revista de Etologia, 9, 21-30.

Bertassoni, A., \& Ribeiro, M. C. (2019). Space use by the giant anteater (Myrmecophaga tridactyla): A review and key directions for future research. European Journal of Wildlife Research, 65, I93.

Carlstead, K., Fraser, J., Benett, C., \& Kleiman, D. G. (1999). Black rhinoceros (Diceros bicornis) in US zoos: II Behavior, breeding, success and mortality in relation to housing facilities. Zoo Biology, 18, 35-52.

Catapani, M. L., Molina, K. T., Lopes, A. M., \& Miranda, F. (2019). Report of three non-agonistic encounters of free-living giant anteaters (Myrmecophaga tridactyla). Edentata, 20, 31-34.

Cless, I. T., \& Lukas, K. E. (2017). Variables affecting the manifestations of and intensity of pacing behavior: A preliminary case study in zoo-housed polar bears. Zoo Biology, 36, 307-315.

Cless, I. T., Voss-Hoynes, H. A., Ritzmann, R. E., \& Lukas, K. E. (2015). Defining pacing quantitatively: A comparison of gait characteristics between pacing and non-repetitive locomotion in zoo-housed polar bears. Applied Animal Behaviour Science, 169, 78-85.

Clubb, R., \& Mason, G. (2003). Captivity effects on wide-ranging carnivores. Nature, 425, 473-474.

Coe, J. C. (2004). Mixed species rotation exhibits. 2004 ARAZPA Conference Proceedings. Australia, on CD.

De Rouck, M., Kitchener, A. C., Law, G., \& Nelissen, M. (2005). A comparative study of the influence of social housing conditions on the behavior of captive tigers (Panthera tigris). Animal Welfare, 14, 229-238.

Desbiez, A. L., \& Medri, Í. M. (2010). Density and habitat use by giant anteaters (Myrmecophaga tridactyla) and southern tamanduas (Tamandua tetradactyla) in the Pantanal wetland, Brazil. Edentata, 11, 4-10.

Diniz, M., \& Brito, D. (2012). The charismatic giant anteater (Myrmecophaga tridactyla): A famous John Doe? Edentata, 13, 76-83.

Dugard, P., File, P., \& Todman, J. (2012). Single-case and small-n experimental designs: A practical guide to randomization tests, 2 nd ed. Routledge.

Eisenberg, J. F., \& Redford, K. H. (1999). Mammals of the Neotropics: The central Neotropics: Ecuador, Peru, Bolivia, Brazil, Vol. 3. University of Chicago.

Gaudin, T. J., Hicks, P., \& Di Blanco, Y. (2018). Myrmecophaga tridactyla (Pilosa: Myrmecophagidae). Mammalian Species, 50, 1-13.

Kreutz, K., Fischer, F., \& Linsenmair, K. E. (2009). Observations of intraspecific aggression in giant anteaters (Myrmecophaga tridactyla). Edentata, 8-10, 6-7.

Kreutz, K., Fischer, F., \& Linsenmair, K. E. (2012). Timber plantations as favourite habitat for giant anteaters. Mammalia, 76, 137-142.

Mason, G. J. (1991). Stereotypies: A critical review. Animal Behavior, 41, 1015-1037.

Mason, G., Clubb, R., Latham, N., \& Vickery, S. (2007). Why and how should we use environmental enrichment to tackle stereotypic behavior? Applied Animal Behavior Science, 102, 163-188.

McPhee, M. E., \& Carlstead, K. (2010). The importance of maintaining natural behaviors in captive mammals. In D. G. Kleiman, K. Thompson, \& C. K. Baer (Eds.), Wild mammals in captivity: Principles and techniques for zoo management, 2nd ed. (pp. 303-313). University of Chicago Press.

Mellen, J., Hayes, M., \& Shepherdson, D. (1998). Captive environments for small felids. In D. Shepherdson, J. Mellen, \& M. Hutchins (Eds.), Second nature: Environmental enrichment for captive animals (pp. 184201). Smithsonian Institution Press.

Miller, L. J., Bettinger, T., \& Mellen, J. (2008). The reduction of stereotypic pacing in tigers (Panthera tigris) by obstructing the view of neighbouring individuals. Animal Welfare, 17, 255-258.

Miranda Junior, J. F., \& Bertassoni, A. (2014). Potential agonistic courtship and mating behavior between two adult giant anteaters (Myrmecophaga tridactyla). Edentata, 15, 69-72.

Morgan, K. N., \& Tromborg, C. T. (2007). Sources of stress in captivity. Applied Animals Behaviour Science, 102, 262-302.

Mouráo, G., \& Medri, I. M. (2007). Activity of a specialized insectivorous mammal (Myrmecophaga tridactyla) in the Pantanal of Brazil. Journal of Zoology, 271, 187-192. 
Powell, D. M., \& Watters, J. V. (2017). The evolution of the animal welfare movement in U.S. zoos and aquariums. Der Zoologische Garten, 86, 219-234.

Rocha, F., \& Mourao, G. (2006). An agonistic encounter between two giant anteaters (Myrmecophaga tridactyla). Edentata, 7, 50-51.

Rodrigues, F. H., Medri, Í. M., De Miranda, G. H., Camilo-Alves, C., \& Mouráo, G. (2008). Anteater behavior and ecology. In S. Vizcaino \& W. J. Loughry (Eds.), The biology of Xenarthra (pp. 257-268). University Press of Florida.

Rose, P. E., Nash, S. M., \& Riley, L. M. (2017a). Moving forward with zoo welfare assessment: A response to Cooke (2017). Journal of Veterinary Behavior, 22, 75-77.

Rose, P. E., Nash, S. M., \& Riley, L. M. (2017b). To pace or not to pace? A review of what abnormal repetitive behavior tells us about zoo animal management. Journal of Veterinary Behavior, 20, 11-21.

Schmidt, T. L. (2012). Ethogram of the giant anteater (Myrmecophaga tridactyla) in captivity: An experience in the Temaiken Foundation. Edentata, 13, 38-48.

Shaw, J. H., Machado-Neto, J., \& Carter, T. S. (1987). Behavior of free-living giant anteaters (Myrmecophaga tridactyla). Biotropica, 19, 255-259.

Shepherdson, D. (1989). Stereotypic behaviour: What is it and how can it be eliminated or prevented? Ratel, 16, 100-106.

Shepherdson, D. J., Carlstead, K., Mellen, J. D., \& Seidensticker, J. (1993). The influence of food presentation on the behavior of small cats in confined environments. Zoo Biology, 12, 203-216.

Shepherdson, D., Lewis, K. D., Carlstead, K., Bauman, J., \& Perrin, N. (2013). Individual and environmental factors associated with stereotypic behavior and fecal glucocorticoid metabolite levels in zoo housed polar bears. Applied Animal Behaviour Science, 147, 268-277.

Swaisgood, R. R., \& Shepherdson, D. J. (2005). Scientific approaches to enrichment and stereotypies in zoo animals: What's been done and where should we go next? Zoo Biology, 24, 499-518.

Swaisgood, R. R., White, A. M., Zhou, X., Zhang, H., Zhang, G., Wei, R., Hare, V. J., Tepper, E. M., \& Lindburg, D. G. (2001). A quantitative assessment of the efficacy of an environmental enrichment programme for giant pandas. Animal Behaviour, 61, 447-457.

Tan, H., Ong, S., Langat, G., Bahaman, A., Sharma, R., \& Sumita, S. (2013). The influence of enclosure design on diurnal activity and stereotypic behaviour in captive Malayan sun bears (Helarctos malayanus). Research in Veterinary Science, 94, 228-239.

Troxell-Smith, S. M., \& Miller, L. J. (2016). Using natural history information for zoo animal management: A case study with okapi (Okapia johnstoni). Journal of Zoo and Aquarium Research, 4, 38-41.

Ward, S. J., Sherwen, S., \& Clark, F. E. (2018). Advances in applied zoo animal welfare science. Journal of Applied Animal Welfare Science, 21, 23-33.

Wark, J. D., Cronin, K. A., Niemann, T., Shender, M. A., Horrigan, A., Kao, A., \& Ross, M. R. (2019). Monitoring the behavior and habitat use of animals to enhance welfare using the ZooMonitor App. Animal Behavior and Cognition, 6, 158-167.

Whitham, J. C., \& Miller, L. J. (2019). A zoo animal's neighbourhood: How conspecific neighbours impact welfare. Animal Welfare, 28, 127-136. 